J. Clin. Chem. Clin. Biochem.

Vol. 17, 1979, pp. 593-597

\title{
A Simple, Automatic Means of Designing a Conversion Table for Expressing Laboratory Results in the International System of Units (SI)
}

By A. Deom,

Cantonal Hospital, Geneva,

J.-M. Aeschlimann,

Zyma Ltd, Nyon and

A. Aellig

District Hospital, Nyon, Switzerland

(Received November 8, 1978/March 2, 1979)

Summary: A simple, automatic means of designing a conversion table for expressing laboratory results in the international system of units (SI) is described.

The increasing use of the international system of units for expressing the results of clinical chemistry and haematology sets doctors, biologists and paramedical workers the problem of converting the results from the previous confused system of units into the SI system.

We propose a simple method for establishing a conversion scale from one system to the other, irrespective of the parameter.

This is based on a Hewlett-Packard 9830A calculator equipped with a 9862A plotter. The BASIC language is used.

Accordingly we have prepared conversion tables for the most commonly used parameters into the international system of units, on behalf of the Swiss Academy of Medical Sciences.

Ein einfaches, automatisches Verfahren zur Erstellung einer Tabelle für die Umrechnung von Laboratoriumsergebnissen in Einheiten des Internationalen Maßsystems (SI)

Zusammenfassung: Es wird über ein einfaches, automatisches Verfahren zur Erstellung einer Tabelle für die Umrechnung von Laboratoriumsergebnissen in Einheiten des Internationalen Maßsystems (SI) berichtet.

Klinisch-chemische und hämatologische Laboratoriumsergebnisse werden heute mehr und mehr in Einheiten des Internationalen Maß̈systems angegeben, so daß sich Ärzte, Biologen und paramedizinische Berufe vor das Problem gestellt sehen, ihre nach dem bisher benutzten konfusen Maßsystem ausgedrückten Ergebnisse in Einheiten des SISystems umzurechnen.

Die Autoren schlagen eine einfache Methode vor, eine Tabelle anzulegen, mit der diese Umrechnungen von einem ins andere System für jede Kenngröße möglich sind.

Verwendét wird ein Hewlett-Packard 9830 A Rechengerät, das einen Aufzeichner 9862 A besitzt. Die Programmierung erfolgt in BASIC.

Nach dieser im folgenden beschriebenen Methode wurden für die Schweizerische Akademie der Medizinischen Wissenschaften derartige Umrechnungstabellen für die gebräuchlichsten Kenngrößen angelegt. 


\section{Introduction}

The continually increasing use of the international system of units for expressing laboratory results, particularly in clinical chemistry, sets doctors, biologists and paramedical workers the problem of converting the results from the former system $(\mathrm{mg} / 100 \mathrm{ml}, \mathrm{g} / \mathrm{l}$, meq/l) into the new one $(\mathrm{mol} / \mathrm{l})$. Easily read conversion tables with a dual scale are a valuable asset.

The present article gives a simple method that avoids lengthy calculations and makes use of a desk calculator for automatically tracing a dual scale in the former and in the new system of units. Moreover, linear or logarithmic expression may be chosen, as desired.

\section{Material}

This study was made with a Hewlett-Packard type 9830A desk calculator equipped with a 9862 plotter.

The type of programme language was the BASIC language adjusted to the model 30 calculator.

\section{Method}

Conversion of a value in the former system of units to the new molar system is reduced to a simple linear relationship without off-set:

$$
\mathrm{V}^{\prime}=\mathrm{C} \times \mathrm{V}
$$

$\mathrm{V}^{\prime}=$ value in the new molar system

$\mathrm{V}=$ value in the former system

$\mathrm{C}=$ conversion coefficient.

For example, for $1.2 \mathrm{mg} / 100 \mathrm{ml}$ bilirubin, where the coefficient $C$ is 17.1 , a value of $17.1 \times 1.2=20.52 \mu \mathrm{mol} / 1$ is obtained.

When a scale in both systems (see Fig. 1) is expressed graphically, adjustment of the curve becomes rather tedious, especially if logarithmic expression has been chosen. It is noteworthy that the latter is coming into increasingly greater use, which is a logical outcome of the frequency distribution of the measurements.
Let D1 and F1 be the initial and final values expressed in the former system and $D^{\prime} 2$ and $F^{\prime} 2$ the initial and final values desired in the new system. The absolute minimum of D1 and D2 =

$\frac{D^{\prime} 2}{C}$ will be $D$ and the absolute maximum of $F 1$ and $F 2=F^{\prime} 2$ will be $\mathrm{F}$.

(F and $D$ are the values in the former system). The maximum length of the scale will be determined by the product of $(F-D)$ and an enlargement factor $(\alpha)$.

\section{Linear expression}

A value $V$ corresponds to the size shown on the graph: $R(V)=$ $\alpha \cdot V$ (the starting point is fixed by the SCALE instruction of the plotter).

Expression of (V-D) becomes strictly proportional to expression of $(F-D)$ with the factor

$\frac{V-D}{F-D}$ :

$$
R(V-D)=R(F-D) \times \frac{V-D}{F-D}
$$

$R(F-D)=$ size fixed by manual adjustment on the plotter and the programme instruction SCALE

$\frac{\mathrm{V}-\mathrm{D}}{\mathrm{F}-\mathrm{D}}=$ calculated size.

Therefore each value $V$ may be expressed independently of the initial adjustment of the plotter and the programme instruction SCALE D-E, F+E, . . (E = margins).

Logarithmic expression

Similarly a value $\mathrm{V}$ is given by:

$R(V)=\alpha \cdot \log V$ so that:

$R(V-D)=R(F-D) \times \frac{\log V}{\log \frac{F}{D}}$

$R(F-D)=$ initially fixed size

$\frac{\log \frac{V}{D}}{\log \frac{F}{D}}=$ calculated size
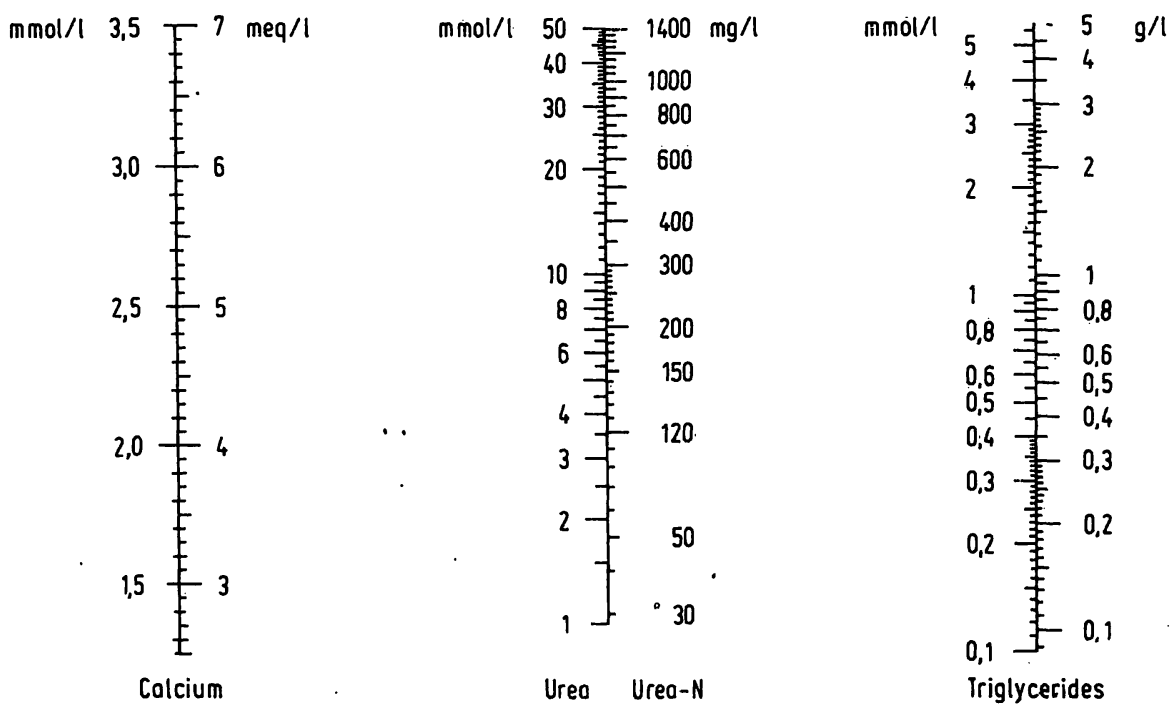

Fig. 1. Conversion scales 
Description and Utilization of Programme (see figs. 2 and 3)

We start the programme after manual adjustment of the record sheet on the plotter. The value of the conversion coefficient for the given unit system (former) into the molar system (new) is then inserted (programme line 10 and 20 ), followed by the areas to be represented in both systems (30 to 60 ).

The machine then calculates the maximum width of the expression (F-D) that is plotted (70 to 150).
The next step is to choose the expression: linear or logarithmic (160 to 170$)$.

Subsequently we try to express one of the systems (former or new: 180-190) and select how the scale is plotted in it (length of graduations, start and end, spacing) (210-250).

Simultaneously we may or may not choose to record the value corresponding to these graduations (labelling) (290-300).



Fig. 2. Flow chart 


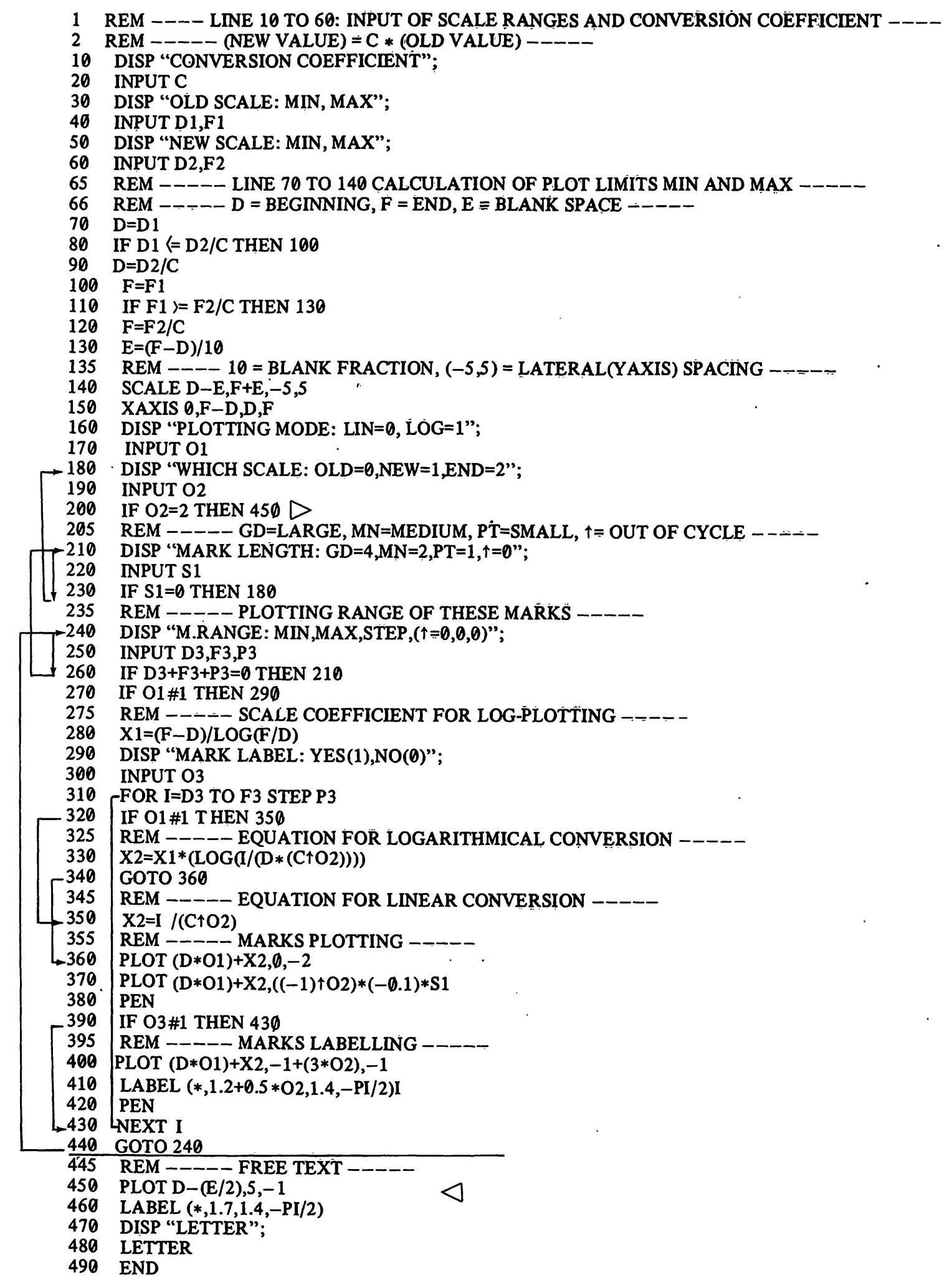

Fig. 3. Program (REM = non-executable remarks) 
Processing is automatic according to the selected instructions and the same questions arise once more in an order that allows different types of scales to be chosen in the scale composition. Change to other specifications, or even to expression of another system, is operated through the answers corresponding to the $\uparrow$ sign of the calculator.

\section{Applications}

This programme has been used to compile a conversion table published by the Size and Units Subcommittee of the Laboratory Committee of the Swiss Academy of Medical Sciences.

In the original version, the reference values are shown by coloured overprinting.

\section{Reference}

1. World Health Organization (1977): The SI for the health professions, WHO, Geneva, 76 pp.

Dr. A. Deom

Laboratoire Central, Hopital Cantonal CH-1211 Genève 4 


$$
\text { . }
$$

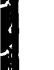$$
\text { , }
$$$$
\text { . }
$$$$
\text { . }
$$

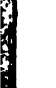

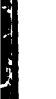



